\title{
Determining the Technical Efficiency of Specialty Ophthalmology Hospital Using SFA and DEA: 2009-2011
}

\author{
Majid Heydari' ${ }^{1}$ Azadeh Ahmadzadeh Ghasab², Haleh Mousavi Isfahani², \\ Mehdi Raadabadi ${ }^{3}$, Mohsen Barouni4* ${ }^{*}$ \\ ${ }^{1}$ Health Services Management, Health Management and Economics Research Center, School of Health \\ Management and Information Sciences, Iran University of Medical Sciences, Tehran, Iran \\ ${ }^{2}$ Health Services Management, Hospital Management Research Center, Iran University of Medical Sciences, \\ Tehran, Iran \\ ${ }^{3}$ Health Economic, Students Scientific Research Center (SSRC), Tehran University of Medical Sciences, Tehran, Iran \\ ${ }^{4}$ Research Center for Health Services Management, Institute for Futures Studies in Health, Kerman University \\ of Medical Sciences, Kerman, Iran \\ Email: ${ }^{*}$ mohsenbarouni@yahoo.com
}

Received 28 December 2013; revised 3 February 2014; accepted 12 February 2014

Copyright (C) 2014 by authors and Scientific Research Publishing Inc.

This work is licensed under the Creative Commons Attribution International License (CC BY). http://creativecommons.org/licenses/by/4.0/

(c) $\underset{\mathrm{EY}}{\mathrm{B}}$ Open Access

\section{Abstract}

Introduction: During the last decade, the health sector of many countries in general has been faced significantly with the increase of health care costs and in particular with the growth in hospital costs, that a significant part of it is due to the inefficient use of resources. The present study has been calculated the technical efficiency of the Specialty Ophthalmology Hospital of Tehran University of Medical Sciences by the comprehensive data analysis methods and stochastic frontier analysis. Methods: In this article, the technical efficiency of the Specialty Ophthalmology Hospital of Tehran University of Medical Sciences has been calculated by the years of 2009 to 2011, by the comprehensive data analysis methods and stochastic frontier analysis. For this purpose, the form of input-oriented data envelopment analysis approach was used by assuming the variable Productivity to scale and stochastic frontier analysis method and from the five output, the occupied bed days, outpatient admissions, inpatient admissions, inpatient days and bed occupancy factor, and from the six output, it means active beds, number of doctors, nurses, and other personnel, budget and equipment costs were used for the study. For data analyzing, Deap software, edit 1/2 and Frontier edit 1/4, was used. Result: The results of a comprehensive data analysis method showed: 1) The capacity of improving technical efficiency in the studied sector is $34 \%$ (average technical efficiency is 0.663 parts); and 2) some of the sectors are met the excess inputs (factors of produc-

\footnotetext{
*Corresponding author.
} 
tion). Technical efficiency using stochastic frontier analysis was equal to 0.937 . In fact, the stochastic frontier analysis showed the inefficiency is less than the actual value. Conclusion: Reducing excess capacity factors (factors of production) should be conducted in the form of a comprehensive plan and by considering all regarded aspects, that this reduction plays a major role in the hospital and health sector costs reduction.

\title{
Keywords
}

\author{
Technical Efficiency; Data Envelopment Analysis; Stochastic Frontier Analysis; Input; Output
}

\section{Introduction}

Dramatic changes in the current era of knowledge management, the existence of monitoring and evaluation system is inevitable, such that any organization needs urgently the evaluation system to be aware of the utility and desirability of their activities [1]. One of the effective management tools is having a consistent and impartial monitoring and evaluation system, which through its results leads the organization to achieve the maximum efficiency [2]. During the last decade, the health sectors of many countries are faced generally with significant increases in health care costs and hospital costs. This problem is due to the impact of combination of factors of the demand such as demographic and epidemiological changes, with factors associated with presentation include the advanced technology and inadequate information available for customers and consumers of health care. Besides these factors, surveys and studies show that, this cost increase can be at least partly due to inefficient use of resources [3]. According to dedication of significant proportion of the state budget to the health sector, the necessity of hospital services assessment is not covered by the public [4]. Because the hospitals as one of the major institutions of health care providers, has special sensitive and importance on economics [5]. In addition, these centers, have allocated a large percentage of health sector resources to themselves, therefore, optimal use of them is very important, which they are considered as key consumers of health care system resources [6]. Obviously, the lack of efficiency and effectiveness of such a major part in the development of social welfare services, not only reduces the quality of life, but also precludes recovery in other sectors, increasing social injustice and inequality, rising health care costs and at last make political problems [7]. However, providing it will be followed by ensuring the health, and also full productivity of health institutions with the appropriate fee [8]. Iranian hospitals use a large part of GDP and consume health care budgets [9] and by emerging the need to ensure the best use of scarce resources and the improve of efficiency of health care delivery, some action to prevent or reduce the resources devoted to this sector of the health care system, will be important. One of these measures is performing the comparisons between Outputs and data in order to estimate the efficiency and productivity of hospitals [10]. Performance measurement and evaluation is done by various methods, in most studies that conducted in the field of performance, the analysis method is used. In this case, the performance has shown by a fraction that output is as numerator and input as denominator. Since this method is used for measuring the effectiveness of input and output, when the studied issue is associated to the communication between an input and some outputs or multiple inputs and outputs, it is restricted [11]. Given the hospital is an organization that has facing simultaneously with multiple outputs and inputs, thus measuring the performance by these methods alone cannot answer. The literature review shows that to overcome these limitations about measuring hospitals' technical efficiency data envelopment analysis (DEA: data envelopment analysis) can be used [12]. Data envelopment analysis is a nonparametric mathematical programming approach that estimates boundary function by using all observations, which is known by this name due to encompass all the data. Nonparametric method based on a set of optimization using linear programming. In this way, the efficient frontier curve is created by points which are determined by linear programming. However, there are several methods for determining efficiency, which each of them has advantages and disadvantages, and determining the best method can be an appropriate strategy of production efficiency for the management. So in this regard, this article has been tried to calculate the performance of the different units of specialty Ophthalmology Hospital of Tehran University of Medical Sciences, using the DEA and SFA software, and also compare their performance with each other, and identify efficient and inefficient units. 


\section{Materials and Methods}

This study is a descriptive-analytical study that were performed in 2011 in Female 1, Female 2, Male 1, Male 2, EMS and hospital outpatient units of Farabi specialty Ophthalmology of Tehran University of Medical Sciences, to determine the effectiveness of the studied units by the DEA and SFA.

In this study, to estimate the technical efficiency, the form of input-oriented data envelopment analysis approach was used by assuming the variable productivity to scale and stochastic frontier analysis method. In the data envelopment analysis method, the linear programming technique is used, and efficiency was calculated separately for each firm by a series of optimization. To determine the different efficacy, of different data analysis method, Deap software edit 1/2 and for the stochastic frontier analysis software Frontier edit 1/4, was used to analyze the data and determine performance. Stochastic frontier analysis and data envelopment analysis models with five output; the occupied bed days, outpatient admissions, inpatient admissions, inpatient days and bed occupancy factor, and from the six output; active beds, number of doctors, nurses, and other personnel, budget and equipment costs were analyzed. Data collecting methods were observation, interviews and investigate documents and statistics were studied. Information was gathered by designed forms according to the study's variables from different units. It is noteworthy that because the number of studied input and output was more than the number of firms (in studied units), (number of firms should be 3 times of the total input and output), Deap software was not able to analyze the data, variables deletion was not reasonably too, so after consultation with the Head of the Departments, with respect to the degree of importance of each input and output in their point of view, we assigned the ratio to each of the output and inputs from 1, then these coefficients were multiplied together in each of these variables to have one input and output instead of five output and six inputs. Then the analysis was performed on this basis.

\section{Results}

The results of kinds of performance calculation by data envelopment analysis using Deap analysis software 2.1 are summarized in Table 1. The average technical efficiency of the studied units using data envelopment analysis by assuming variable returns to scale is 0.663 , in other words, based on the results of the model, the capacity to enhance the efficiency of studied units, without any increase in the cost and by using the same amount of inputs, is about 34 percent. Also average of management performance (net performance) of the sections is 0.769 and average performance to scale is 0.803 . Also the highest level of technical efficiency was in 1388 with technical efficiency of 0.709 and the lowest level of technical efficiency was in 1389 with technical efficiency of 0.577 , which are summarized in Table 2.

Average of technical efficiency of the Farabi hospital units is equal to 0.937 that is achieved by using the SFA during the 1388, 89 and 90, which is summarized in Table 3. In Table 4, sectors' returns to scale are shown in separated years and Table 5 also contains the reference set for the sectors.

Table 1. Comparison of technical and managerial efficiency and scale of studied units using data envelopment analysis (DEA) model.

\begin{tabular}{|c|c|c|c|c|c|c|c|c|c|}
\hline \multirow{2}{*}{ Unit Name } & \multicolumn{3}{|c|}{ In 1388} & \multicolumn{3}{|c|}{ In 1389} & \multicolumn{3}{|c|}{ In 1390} \\
\hline & $\begin{array}{l}\text { Technical } \\
\text { Efficiency }\end{array}$ & Management & $\begin{array}{c}\text { Scale } \\
\text { Performance }\end{array}$ & $\begin{array}{l}\text { Technical } \\
\text { Efficiency }\end{array}$ & Management & $\begin{array}{c}\text { Scale } \\
\text { Performance }\end{array}$ & $\begin{array}{l}\text { Technical } \\
\text { Efficiency }\end{array}$ & $\begin{array}{l}\text { Management } \\
\text { Performance }\end{array}$ & $\begin{array}{c}\text { Scale } \\
\text { Performance }\end{array}$ \\
\hline Female 1 & 0.943 & 1.000 & 0.943 & 0.679 & 0.679 & 1.000 & 1.000 & 1.000 & 1.000 \\
\hline Female 2 & 0.833 & 0.873 & 0.955 & 0.452 & 0.480 & 0.941 & 0.731 & 0.771 & 0.948 \\
\hline Male 1 & 0.777 & 0.824 & 0.943 & 0.630 & 0.630 & 1.000 & 0.908 & 0.908 & 1.000 \\
\hline Male 2 & 0.680 & 0.721 & 0.943 & 1.000 & 1.000 & 1.000 & 0.705 & 0.705 & 1.000 \\
\hline Emergency & 1.000 & 1.000 & 1.000 & 0.684 & 0.880 & 0.778 & 0.841 & 1.000 & 0.841 \\
\hline Outpatient & 0.020 & 0.325 & 0.062 & 0.018 & 0.371 & 0.048 & 0.035 & 0.684 & 0.051 \\
\hline Average & 0.709 & 0.790 & 0.808 & 0.577 & 0.673 & 0.794 & 0.703 & 0.845 & 0.807 \\
\hline
\end{tabular}


Table 2. Comparison of technical and managerial efficiency and scale of studied units in separated years by using (DEA) method.

\begin{tabular}{cccc}
\hline $\begin{array}{c}\text { Average of } \\
\text { scale efficiency }\end{array}$ & $\begin{array}{c}\text { Average of management } \\
\text { performance }\end{array}$ & $\begin{array}{c}\text { Average of technical } \\
\text { performance }\end{array}$ & Average \\
\hline 0.808 & 0.790 & 0.709 & 1388 \\
0.794 & 0.673 & 0.577 & 1389 \\
0.807 & 0.845 & 0.703 & 1390 \\
0.803 & 0.769 & 0.663 & Total \\
\hline
\end{tabular}

Table 3. Comparison of technical efficiency of studied units using the Stochastic Frontier Analysis (SFA) method.

\begin{tabular}{cccc}
\hline & & Technical Efficiency & \\
\cline { 2 - 4 } Unit Name & 1388 & 1389 & 0.93 \\
\hline Female 1 & 0.94 & 0.94 & 0.92 \\
Female 2 & 0.94 & 0.93 & 0.93 \\
Males 1 & 0.93 & 0.94 & 0.92 \\
Males 2 & 0.93 & 0.94 & 0.93 \\
Emergency & 0.94 & 0.94 & 0.93 \\
Outpatient & 0.93 & 0.94 & \\
\hline Average & & 0.937 & \\
\hline
\end{tabular}

Table 4. Rate of efficiency to units’ scale in separate years of study.

\begin{tabular}{cccc}
\hline & & Rate of Efficiency to Scale & \\
\cline { 2 - 4 } Unit Name & 1388 & 1389 & 1390 \\
\hline Female 1 & Increasing & constant & constant \\
Female 2 & Increasing & Decreasing & Decreasing \\
Males 1 & Increasing & constant & constant \\
Males 2 & Increasing & constant & constant \\
Emergency & constant & Decreasing & Decreasing \\
Outpatient & Decreasing & Decreasing & Decreasing \\
\hline
\end{tabular}

Table 5. Reference set for the sectors.

\begin{tabular}{|c|c|c|c|}
\hline \multirow{2}{*}{ Unit Name } & \multicolumn{3}{|c|}{ Reference Set } \\
\hline & 1388 & 1389 & 1390 \\
\hline Female 1 & Female 1 & Males 2 & Female 1 \\
\hline Female 2 & Emergency & Males 2 & Female 1-Emergency \\
\hline Males 1 & Female 1 & Males 2 & Female 1 \\
\hline Males 2 & Female 1 & Males 2 & Female 1 \\
\hline Emergency & Emergency & Males 2 & Emergency \\
\hline Outpatient & Emergency & Males 2 & Emergency \\
\hline
\end{tabular}




\section{Discussion \& Conclusion}

The average of technical efficiency of the hospital studied sector, with the assumption of variable returns to scale, is 0.663. In a research that Hajialiafzali and colleagues have done in the Social Security hospitals, the average technical efficiency in these hospitals is obtained 0.9 [13]. This shows that technical efficiency is higher in these hospitals. In a study that was done by Ganon to assess the technical efficiency in Ireland hospitals, the average technical efficiency is obtained 0.952 from 1995 to 2000, which this rate is higher than the average level of technical efficiency obtained in this study [14]. Technical efficiency by using assumption of variable returns to scale was divided into two principal components, and so average of management performance (net performance) of units is 0.769 and average of performance to scale is obtained 0.803 . The results indicated that the hospitals units do not operate efficiently, and the capacity of increasing technical efficiency is 34\%. In a study that Ghaderi performed to determine the technical efficiency of hospitals in Iran University of Medical Sciences, the average of technical efficiency is equal to 0.893 , the average managerial efficiency is 0.922 , and the average of scale efficiency is 0.966 [15]. Also, Pourreza and colleagues achieved to the average technical efficiency of 0.972 in their study, the average managerial efficiency was0.995 and average efficiency to scale was 0.976 [16].

The results show that the average technical efficiency obtained for the units using Stochastic Frontier Analysis (SFA) is higher than average technical efficiency obtained using data envelopment analysis (DEA). Perhaps it is because the DEA method considers all deviations of the efficient frontier curve resulting from non-performance of units, and considers it as inefficiency part, however Stochastic Frontier Analysis divide function's deviations in two inefficiency and disruption parts and therefore efficiency in SFA method is shown higher than other methods. Average technical efficiency using SFA is equal to 0.937, and while the average technical efficiency using DEA method is equal to 0.663 . In fact, SFA method shows inefficiency less than the actual value.

In present study, the most technical performance rate was in 1388 with technical performance of 0.709 and the lowest technical efficiency was in 1389 with technical efficiency of 0.577 . Also the highest level of management performance was in 1390 with net efficiency of 0.845 and the lowest was in 1389 with net efficiency of 0.673 . Scale performance, had the highest rate in 1388 with a performance of 0.808 and lowest level in 1389 with 0.794. It is possible to consider closure of some parts of hospitals, more than 3 months, as a factor of efficiency reduction in 1389. The results also show that in 1388, 66 percent of hospital's unit have increasing returns to scale, 16 percent have descending returns to scale and 16 percent also have constant return to scale. In 1389 , 50 percent of units have had descending returns, and 50 percent have had a constant return to scale. Also in 1390 , 50 percent of units have had descending returns, and 50 percent have had constant return to scale. In other words, half of these units in the two years had act at the most efficient scale of production.

In the data envelopment analysis method for any non-performance firms, an effective agent or combination of two or more active firms are introduced as the reference and pattern firms. In other words, this method selects some firms as a reference entity and other firms due to the given weight can achieve the optimum level. In this study in 1388, Female 1 and emergency units were introduced as reference agencies to other departments. Also in 1389, Male 2 was introduced as business model, and in the first half of 1390, Female 1 and emergency units were introduced as business model for other departments.

The results show that in some units, especially the outpatient department, are facing with additional inputs (factors of production) that the reduction of this excess capacity should be conducted in the form of a comprehensive plan and be done with consideration of all aspects.

\section{References}

[1] Despotis, D.K. (2005) A Reassessment of the Human Development Index via Data Envelopment Analysis. Operational Research Society Journal, 56, 969-980. http://dx.doi.org/10.1057/palgrave.jors.2601927

[2] Charnes, A., Cooper, W.W. and Rhodes, E. (1978) Measuring the Efficiency of Decision Making Units. European Journal of Operational Research, 2, 429-444. http://dx.doi.org/10.1016/0377-2217(78)90138-8

[3] Sabermahani, A., Barouni, M., Hadian, M. and Ghaderi, H. (2012) Comparing the Efficiency of Kerman Province Towns in Acquiring Human Development Index via Data Envelopment Analysis, IRCMJ, 14, 248-249.

[4] Scarpello, V.G. and Ledvinka, J. (1988) Personnel/Human Resource Management: Environment and Function. PWS-Kent Pub., Boston.

[5] Askari, R., Goudarzi, R., Fallahzadeh, H., Zarei, Ba. and Dehqani Tafti, A. (2011) Efficiency Appraisal Of Yazd University of Medical Science Hospitals by Quantitative Approach Data Envelopment Analysis (DEA). Payavard Salamat, 
6, 215-224.

[6] Jacobs, P. and Rapoport, J. (2004) The Economics of Health and Medical Care. Jones \& Bartlett Learning, Burlington.

[7] Karimi, S., Sajadi, H., Karami, M., Torkzad, L. and Bidram, R. (2009) Efficiency Estimation in General Hospitals of Isfahan University of Medical Sciences during 2005-2006 by Data Envelopment Analysis. Journal of Health Administration, 12, 39-46

[8] Tabibi, S., Maleki, M., Movahednia, S. and Gohari, M. (2009) Relationship between Hospitals Ownership and Performance Assessment Score of Emergency Departments in the Hospitals Affiliated to Iran University of Medical Sciences 2007. Journal of Health Administration, 12, 25-32.

[9] World Bank (2001) Iran National Health Accounts, World Bank Report. Ministry of Health and Medical Education, Tehran.

[10] Jacobs, R. (2001) Alternative Methods to Examine Hospital Efficiency: Data Envelopment Analysis and Stochastic Frontier Analysis. Health Care Management Science, 4, 103-115. http://dx.doi.org/10.1023/A:1011453526849

[11] Magnussen, J. (1996) Efficiency Measurement and the Operationalization of Hospital Production. Health Services Research, 31, 21-27.

[12] Hatam, N. (2008) The Role of Data Envelopment Analysis (DEA) Pattern in the Efficiency of Social Security Hospitals in Iran. Iranian Red Crescent Medical Journal, 10, 211-217.

[13] Noorbakhsh, F. (1998) A Modified Human Development Index. World Development, 26, 517-528. http://dx.doi.org/10.1016/S0305-750X(97)10063-8

[14] Gannon, B. (2005) Testing for Variation in Technical Efficiency of Hospitals in Ireland. Economic and Social Review, 36, 273.

[15] Ghaderi, H., Goudarzi, G. and Gohari, M. (2007) Determination Technical Efficiency of Hospitals Affiliated with Iran University of Medical Science by Data Envelopment Analysis (2000-2004). Journal of Health Administration, 9, 39-44.

[16] Charnes, A., Cooper, W.W. and Rhodes, E. (1978) Measuring the Efficiency of Decision Making Units. European Journal of Operational Research, 2, 429-444. http://dx.doi.org/10.1016/0377-2217(78)90138-8 